\title{
Effects of Long-Term Simulated Microgravity on Oxidant and Antioxidant Values in the Plasma and Lung Tissues of Rhesus Macaque
}

\author{
Yang Chen ${ }^{1}$, Ping Wang ${ }^{1, *}$, Chongyu $\mathrm{Xu}^{1}$, Yiling $\mathrm{Cai}^{2}$, Huasong $\mathrm{Ma}^{3}$ \\ ${ }^{1}$ Department of Respiratory Medicine, 306th Hospital of PLA, Beijing, China \\ ${ }^{2}$ Department of Neurology, 306th Hospital of PLA, Beijing, China \\ ${ }^{3}$ Department of Orthopedic, 306th Hospital of PLA, Beijing, China \\ Email address: \\ pingwang306@126.com (Ping Wang) \\ ${ }^{*}$ Corresponding author
}

\section{To cite this article:}

Yang Chen, Ping Wang, Chongyu Xu, Yiling Cai, Huasong Ma. Effects of Long-Term Simulated Microgravity on Oxidant and Antioxidant Values in the Plasma and Lung Tissues of Rhesus Macaque. American Journal of Laboratory Medicine. Vol. 2, No. 1, 2017, pp. 1-6.

doi: $10.11648 /$ j.ajlm.20170201.11

Received: August 14, 2016; Accepted: November 14, 2016; Published: January 18, 2017

\begin{abstract}
This study evaluated the influence of long-term simulated microgravity on oxidative stress and total antioxidant capacity in the plasma and lung tissues of rhesus macaque $\left(-10^{\circ} \mathrm{C}\right.$ head-down tilting). Fifteen healthy male rhesus macaques were randomly divided into groups 1 (control, $\mathrm{n}=5$ ), groups 2 (head-down tilting for 6 weeks, $\mathrm{n}=5$ ) and groups 3 (head-down tilting for 6 weeks and recover from 4 weeks, $n=5$ ). Oxidative stress was evaluated by critical SOD, GSH, $\mathrm{H}_{2} \mathrm{O}_{2}$ in plasma and SOD, GSH in lung tissues. HE staining was used to observe the histopathological structure changes of pulmonary tissues. CAT, SOD1, SOD2, SOD3, GPX1, GPX4, GPX7, PRDX1, HMOX1, ALOX5 and DUOX1 mRNA were measured by real-time PCR. GSH concentration was significantly decreased, whereas $\mathrm{H}_{2} \mathrm{O}_{2}$ level was significantly increased in group 2 compared with group 1 and group 3 . Compared to group 1, histopathological examination revealed alveolar septal thickening, and alveolar and interstitial lymphocytic infiltration in group 2 and group 3 and the pathological changes in group 3 were smaller than those in group 2. Group 2 and group 3 showed significant up-regulation of SOD3 gene compared with group 1 by real-time PCR. In a long-term simulated microgravity environment, systemic antioxidant level of GSH was reduced but an oxidative stress marker of $\mathrm{H}_{2} \mathrm{O}_{2}$ was increased. Meanwhile, long-term simulated microgravity caused lung injury and induced the mRNA of SOD3 expression in lung tissues. But oxidant stress is not a major factor involved in the development of lung damage under simulated microgravity. Further study still clarifies the mechanism about the lung injury under microgravity.
\end{abstract}

Keywords: Simulated Microgravity, Oxidative Stress, GSH, $\mathrm{H}_{2} \mathrm{O}_{2}$

\section{Introduction}

Microgravity is an environmental factor, which inevitably influences the physiological function of the astronauts if they stay in space for a long time $[1,2,3]$. Exposure to microgravity results in severe abnormalities in various organ systems such as a loss of bone mass, cardiovascular fitness and changes in lung functions $[4,5,6,7]$. In particular, the lung is such a vulnerable organ that has great influences on spaceflight [8, 9]. Earlier studies have shown that microgravity affects lung function and causes certain damages to pulmonary tissue $[4,8,9]$. Despite of research on microgravity-induced lung injury, the mechanism for lung injury remains to be identified $[8,9]$.
Antioxidant or oxidant balance perturbation is a common feature in environmental pressure. When the level of oxidation exceeds antioxidant defense, oxidative stress occurs and it can cause irreversible cellular damage [10]. In this study, we evaluated the effects of long-term stimulated microgravity on the lung tissue morphology, the related genes' expression of oxidative stress in lung tissues and oxidative stress parameters in plasma as well as lung tissues by suspending rhesus macaque in the antiorthostatic position $\left(-10^{\circ} \mathrm{C}\right.$ head-down tilting, a model of simulated microgravity $[11,12])$ in order to look for oxidative stress parameters in plasma and to discover the possible mechanisms between oxidative stress and microgravity in lung tissues. 


\section{Materials and Methods}

\subsection{Ethics Statement}

The work described in this study was carried out in China Agricultural Universtiy via a service contract. All animals were placed in the laboratory which was located at China Agricultural University of China Astronaut Training Center. The housing and animal care procedures were in compliance with the Chinese guidelines for animal experiments and the Guide for the Care and Use of Laboratory Animals of Association. The care and experimental use of rhesus macaques was approved by the Scientific Research Training Center for Chinese Astronauts (ACC-IACUC-2014-001).

Rhesus macaques were individually placed in stainless steel mesh cages $(100 \mathrm{~cm} \times 100 \mathrm{~cm} \times 100 \mathrm{~cm}$ dimension $)$ in an air-conditioned building with a temperature between 20 and $24^{\circ} \mathrm{C}$ and a 12 hours artificial light cycle. They were fed with a standard primate diet and had free access to water. Animal health was monitored daily by the animal care and veterinary personnel. Furthermore, additional tools including rings, safe rubber toys and mirrors were also provided.

At the end of this experiment, monkeys that served as donors of blood or lung tissues were sacrificed for the purpose of this study. Monkeys were anesthetized prior to handling (such as for physical examinations and blood collections) and were euthanized first by anesthesia with ketamine (i.m $10 \mathrm{mg} / \mathrm{kg}$ ) and then were killed by bloodletting. Lung tissues were collected for the following experiments.

\subsection{Animal Models and Groups}

Fifteen healthy male rhesus macaques, aged from 4 to 8 years old, weighing from 4 to $8 \mathrm{~kg}$, were supplied by Beijing Institute of Xieerxin Bology Resource (Beijing, China). They were randomly divided into three groups: group 1 (control, $\mathrm{n}=5$ ), group 2 (head-down tilting for 6 weeks, $\mathrm{n}=5$ ) and group 3 (recovery for 4 weeks after 6 weeks of head-down tilting, $\mathrm{n}=5)$. Head-down tilting $\left(-10^{\circ}\right)$ was applied to simulate the microgravity condition. The animal model of head-down tilting is generally accepted in world [11, 12, 13, 14]. Briefly speaking, macaques in group 2 were suspended in a cage and the hind legs hanging on each side by special devices for 6 weeks. The degree between the body ordinate axis and the horizontal plane was $10^{\circ}$. Macaques in group 1 were put in the same cage, however, they could move freely without head-down tilting for 6 weeks. Macaques in group 3 were head-down tilting for 6 weeks and allowed to move freely in the same cage for 4 weeks.

\subsection{Collection of Blood Sample and Tissue}

Peripheral blood samples for various analyses were collected before the animals were anesthetized. Plasma was extracted from blood by centrifugation (3.500 rpm for $10 \mathrm{~min}$ ) and stored at $-80^{\circ} \mathrm{C}$. Lung tissues were quickly removed and stored in liquid nitrogen until the isolation of total RNA was accomplished. Some were immediately fixed in $10 \%$ neutralized formalin solution for histological studies.

\subsection{Histological Studies}

Some pulmonary samples, intended for histological examination by light microscopy, were immediately fixed in $10 \%$ of formalin and processed in a series of graded ethanol solutions. They were then embedded in paraffin, serially sectioned at $4 \mu \mathrm{m}$. The sections were stained with hematoxylin-eosin.

\subsection{Hydrogen Peroxide $\left(\mathrm{H}_{2} \mathrm{O}_{2}\right)$ Measurement Assay}

$\mathrm{H}_{2} \mathrm{O}_{2}$ is one of the most well documented reactive oxygen species (ROS) produced under oxidative stress conditions [15]. $\mathrm{H}_{2} \mathrm{O}_{2}$ production in plasma was measured as quantitative index of ROS generation by OxiSelectTM Hydrogen Peroxide Assay Kit (Cell Biolabs, USA) according to manufacturer's instruction. The samples were performed on monitoring at the absorbance at $570 \mathrm{~nm}$ by the Bio-Rad Model 680 microplate reader. The amount of $\mathrm{H}_{2} \mathrm{O}_{2}$ in plasma was calculated using a standard curve prepared with known concentrations of $\mathrm{H}_{2} \mathrm{O}_{2}$.

\subsection{Superoxide Dismutase (SOD) Measurement Assay}

SOD is one of the most important antioxidative enzymes [16]. SOD in plasma and lung tissues homogenates was measured by OxiSelectTM Superoxide Dismutase Activity Assay Kit (Cell Biolabs, USA) in accordance with manufacturer's instruction. To prepare homogenates, the lung tissues were homogenized with a homogenizer in cold lysis solution $(100 \mathrm{mg} / 1 \mathrm{~mL}$, tissue/buffer, w/v). After centrifugation, the supernatant was separated and used for assay of SOD activities. The samples were performed on monitoring at the absorbance at $490 \mathrm{~nm}$ by the Bio-Rad Model 680 micro-plate reader. The concentration of SOD was calculated using a standard curve prepared with known concentrations of SOD.

\subsection{Glutathione (GSH) Measurement Assay}

GSH helps protect cells from free radical damage by acting as an antioxidant [17]. GSH in plasma and lung tissues homogenates were measured by OxiSelectTM Total Glutathione Assay Kit (Cell Biolabs, USA) on the basis of manufacturer's instruction. To prepare homogenates, perfusion of the lung tissue with a PBS/heparin was performed to prevent coagulation. The blot of the tissue was dried and weighed. The ice-cold 5\% Metaphosphoric Acid (1 mL/100 mg tissue) was added and a homogenizer was utilized to homogenize. The homogenate was centrifuged at $12,000 \mathrm{rpm}$ for $15 \mathrm{~min}$ at $4^{\circ} \mathrm{C}$. Then the supernatant was collected. The sample were performed on monitoring at the absorbance at $490 \mathrm{~nm}$ by the Bio-Rad Model 405 microplate reader. The concentration of GSH was calculated using a standard curve prepared with known concentrations of GSH.

\subsection{Quantitative Real-Time Reverse Transcript-Polymerase Chain Reaction}

Total RNA was isolated from lung tissues using Trizol Reagent (Invitrogen Life Technologies, USA) depending on the manufacturer's protocol. Total RNA was quantified using the ND-1000 spectrophotometer (Nanodrop, Wilmington, DE, USA). The RNA integrity and absence of genomic DNA 
contamination were evaluated by agarosegel electrophoresis.

Complementary DNA was synthesized from $2 \mu \mathrm{g}$ total RNA using a Revert Aid First Strand cDNA Synthesis Kit (Thermo Scientific, USA) following the manufacturer's instructions. Quantitative real-time reverse transcript-polymerase chain reaction (qRT-PCR) was performed using the SYBR Prime Script RT-PCR kit (Takara, Japan) in an Applied Biosystems 7500 Fluorescent Quantitative PCR System (Applied Bio-systems, USA). Total RNA was tested for the expression of 11 genes: catalase (CAT), copper/zinc superoxide dismutase (Cu/Zn SOD, cytosolic-SOD1, SOD1), manganese superoxide dismutase (MnSOD, mitochondrial-SOD2, SOD2), extracellular superoxide dismutase (EcSOD, SOD3), cytosolic glutathione peroxidase (GPX1), phospholipid hydroperoxide glutathione peroxidase (GPX4), non-selenocysteine-containing phospholipid hydroperoxide glutathione peroxidase (NPGPx or GPX7), peroxiredoxin 1 (PRDX1), heme oxygenase 1 (HMOX1), arachidonate 5-lipoxygenase (ALOX5), dual oxidase 1 (DUOX1) and internal standard control gene (GAPDH).

qRT-PCR reactions were performed in triplicate. The relative expression levels of mRNAs between samples were calculated by the comparative delta $\mathrm{CT}$ (threshold cycle number) method (2- $\Delta \Delta \mathrm{CT})$ implemented in the 7500 Real-Time PCR System software. The relative quantification of target gene expression was evaluated by the comparative $\mathrm{CT}(\Delta \mathrm{CT})$ method. The value was determined by subtracting the GAPDH CT value for each sample from the target $\mathrm{CT}$ value of that sample. The representation of $2-\Delta \Delta \mathrm{CT}$ was fold changes in the relative gene expression than of target. Gene-specific primers usage was presented in Table 1.

Table 1. Primer sequence and product size used for qRT-PCR.

\begin{tabular}{|c|c|c|}
\hline Genes & Primer sequence & Product size (bp) \\
\hline CAT & $\begin{array}{l}\text { AGTGATCGGGGGATTCCAGA } \\
\text { AAGTCTCGCCGCATCTTCAA }\end{array}$ & 159 \\
\hline SOD1 & $\begin{array}{l}\text { CGCTCTCAGGAGACCATTCC } \\
\text { GGGCGATCCCAATTACACCA }\end{array}$ & 144 \\
\hline SOD2 & $\begin{array}{l}\text { TCTGTTGGTGTCCAAGGCTC } \\
\text { TGCTCCCACACATCAATCCC }\end{array}$ & 146 \\
\hline SOD3 & $\begin{array}{l}\text { GACATGCACGCCAAGATCAC } \\
\text { AAGAGGACGACTCCGGTCA }\end{array}$ & 143 \\
\hline GPX1 & $\begin{array}{l}\text { TTCGAGCCCAACTTCATGCT } \\
\text { TCTCGAAGTTCCAGGCAACA }\end{array}$ & 184 \\
\hline GPX4 & $\begin{array}{l}\text { GTGAGGCAAGACCGAAGTGA } \\
\text { GTCCCCGTTCACGCATATCT }\end{array}$ & 199 \\
\hline GPX7 & $\begin{array}{l}\text { TTCAACGTACTCGCCTTCCC } \\
\text { AGAAACCACGACTTACGGGC }\end{array}$ & 182 \\
\hline PRDX1 & $\begin{array}{l}\text { TGCCCTACGGAGATCATTGC } \\
\text { CGCTTCGGGTCTGATACCAA }\end{array}$ & 176 \\
\hline HMOX1 & $\begin{array}{l}\text { ACTTCAGAGTGGGCCAAAGG } \\
\text { ATGGCCGTGTCAACAAGGAT }\end{array}$ & 143 \\
\hline ALOX5 & $\begin{array}{l}\text { GACGTCTACGTGTACGGCAT } \\
\text { GAGCATTGGGGATCCAGGAG }\end{array}$ & 172 \\
\hline DUOX1 & $\begin{array}{l}\text { TCCCTGCTCCAGTAGTCTCC } \\
\text { GGCCAGCTCCTTTACTCAGG }\end{array}$ & 175 \\
\hline GAPDH & $\begin{array}{l}\text { GAGCCAAAAGGGTCATCATCT } \\
\text { TGAGTCCTTCCACGATACCAA }\end{array}$ & 180 \\
\hline
\end{tabular}

\subsection{Statistical Analysis}

All statistical analyses were performed by using SPSS version 18.0 (SPSS, Chicago, IL). Differences between groups were assayed through one-way ANOVA and Chi-square test. One-way ANOVA was used to compare quantitative data with normal distributions and equal variance. Chi-square test was utilized to compare categorical data. $\mathrm{P}$ values $<0.05$ were considered statistical significance.

\section{Results}

\subsection{Histopathological Observation of Lung Tissues}

Morphological changes in the lung: the macaque lung in group 1 showed clear lung tissue structure and normal morphology; alveolar walls were uniform and the margin was smooth. In group 2, we observed structural damage of alveolar walls, thickened alveoli septum, interstitial and alveolar mild edema, alveolar hemorrhage and a few of lymphocytes infiltration. And the degree of injury in group 3 was slighter than that of group 2 (Figure 1).
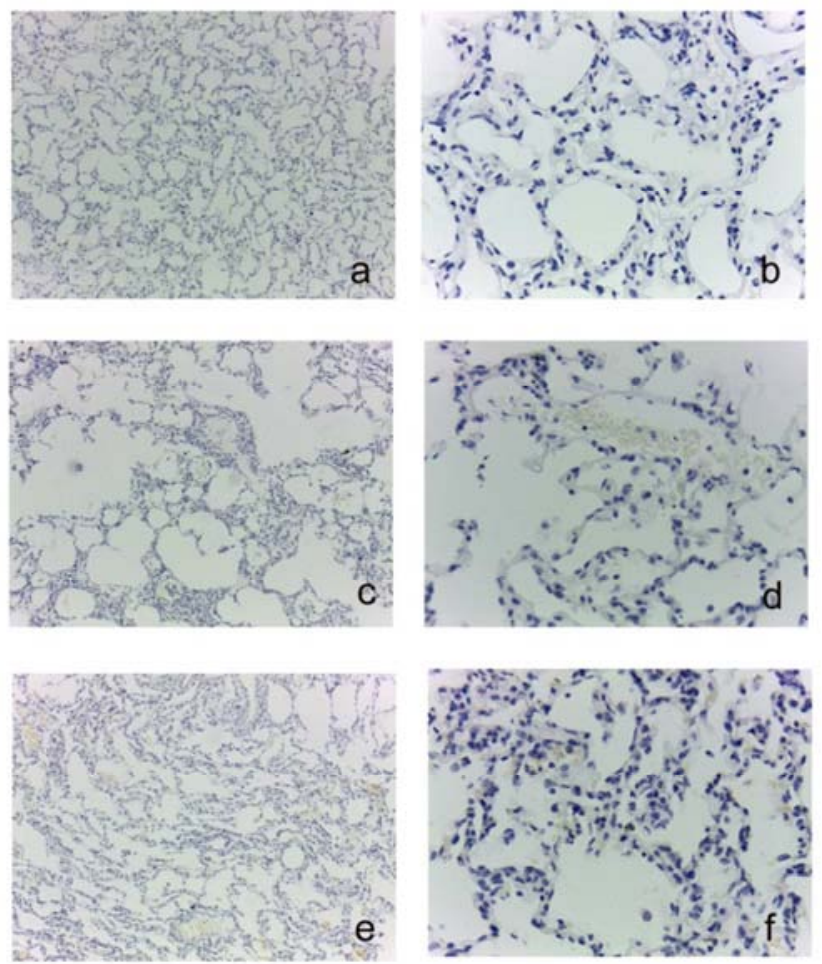

Figure 1. Histopathological analysis of lung paraffin sections stained with HE $(a, c, e \times 100 ; b, d, f \times 400): a$ and $b:$ Group $1 ;$ c and $d:$ Group 2; $e$ and f: Group 3 .

\subsection{Simulated Weightlessness Inducing $\mathrm{H}_{2} \mathrm{O}_{2}$ Production in Plasma of Macaque}

Overproduction of reactive oxygen species (ROS) can produce oxidative stress in tissues and organs. The main ROS currently known are free oxygen radical such as superoxide radicals $(\mathrm{O} 2-)$, hydroxyl free radical $(\mathrm{OH})$ and $\mathrm{H}_{2} \mathrm{O}_{2} \cdot \mathrm{H}_{2} \mathrm{O}_{2}$ is indirect indicator of the free radical O2-[18, 19]. Thus, we determined production of $\mathrm{H}_{2} \mathrm{O}_{2}$ as an indication of ROS formation in plasma of macaque after simulated weightlessness. From Table 2, $\mathrm{H}_{2} \mathrm{O}_{2}$ levels generated in plasma of group 2 significantly increased compared with group 1 and group 3 
$(\mathrm{P}<0.001)$. Therefore, our results suggested that simulated weightlessness induced oxidative stress as well as stimulated plasma to increase $\mathrm{H}_{2} \mathrm{O}_{2}$ production.

Table 2. The concentration of H2O2, SOD, GSH in plasma $(x \pm s)$.

\begin{tabular}{llll}
\hline Groups & $\mathbf{H}_{2} \mathbf{O}_{2}(\boldsymbol{\mu m o l} / \mathbf{L})$ & SOD $(\mathbf{U})$ & GSH $(\boldsymbol{\mu m o l} / \mathbf{L})$ \\
\hline Group 1 & $4.36 \pm 0.74$ & $0.35 \pm 0.04$ & $0.07 \pm 0.01$ \\
Group 2 & $24.74 \pm 0.22^{* *}$ & $0.33 \pm 0.04$ & $0.02 \pm 0.02^{*}$ \\
Group 3 & $4.61 \pm 0.28$ & $0.36 \pm 0.04$ & $0.06 \pm 0.02$ \\
\hline
\end{tabular}

Note: $* \mathrm{P}<0.05$, Group 1 vs Group $2 ; * * \mathrm{P}<0.001$, Group 1 vs Group 2, Group 2 vs Group 3.

\subsection{Activities of SOD and GSH in Plasma and Lung Tissues of Macaque}

It is acknowledged that human antioxidant defense system is equipped with detoxifying enzymes, such as SOD, CAT, and GSH-Px, thiol systems and so on, glutathione (GSH) and lipophilic radical-scavengers, for instance, tocopherols [20]. SOD, an endogenous antioxidant enzyme, provides the first line of defense against ROS [16]. GSH is an intracellular antioxidant thiol, which is considered as the second line of cellular defense against ROS [17]. Hence, as the biomarker of the antioxidant defenses, the activity of SOD and GSH in plasma and lung tissues was measured (Tables 2 and 3). The activities of GSH in plasma were conspicuously decreased in group 2 compared with group 1 and group $3(\mathrm{P}<0.05)$. However, SOD activities in plasma had no significance of difference in these groups. Unfortunately, SOD and GSH levels in lung homogenates did not significantly change in group 1, 2 and 3 (Table 3 ).

Table 3. The concentration of SOD, GSH in lung tissues $(x \pm s)$.

\begin{tabular}{lll}
\hline Groups & SOD $(\mathbf{U})$ & GSH $(\boldsymbol{\mu m o l} / \mathbf{L})$ \\
\hline Group 1 & $0.18 \pm 0.06$ & $0.37 \pm 0.18$ \\
Group 2 & $0.23 \pm 0.07$ & $0.38 \pm 0.18$ \\
Group 3 & $0.19 \pm 0.07$ & $0.35 \pm 0.13$ \\
\hline
\end{tabular}

\subsection{The Effect of Simulated Weightlessness on Antioxidant Gene Expression and the Expression of Oxidant Stress Related Genes in Lung Tissues}

We performed a qRT-PCR analysis in order to determine simulated weightlessness on antioxidant gene expression and the related genes' expression of oxidant stress in lung tissues. The genes included CAT, SOD1, SOD2, SOD3, GPX1, GPX4, GPX7, PRDX1, HMOX1, ALOX5 and DUOX1. Table 4 showed the mRNA expression of the antioxidant genes and oxidant stress of related genes in lung tissue by quantitative detection of gene expression. Group 2 and group 3 showed significant up-regulation of SOD3 gene compared with group 1. Other gene expressions were similar between these groups.

Table 4. Comparison cytokine mRNA expression in lung tissues between group 1, 2, 3.

\begin{tabular}{|c|c|c|c|c|c|}
\hline Genes & $\Delta$ CT of Group $1(x \pm s)$ & $\Delta$ CT of Group $2(x \pm s)$ & $\Delta$ CT of Group $3(x \pm s)$ & $2-\Delta \Delta \mathrm{CT}$ Group $2 / 1$ & $2-{ }^{\Delta \Delta C T \text { Group } 3 / 1}$ \\
\hline CAT & $3.69 \pm 0.71$ & $3.11 \pm 0.66$ & $3.89 \pm 0.78$ & 1.50 & 0.89 \\
\hline SOD1 & $1.56 \pm 0.27$ & $1.96 \pm 0.57$ & $1.93 \pm 0.41$ & 0.80 & 0.78 \\
\hline SOD2 & $2.43 \pm 0.91$ & $2.04 \pm 1.02$ & $1.97 \pm 0.97$ & 1.31 & 1.38 \\
\hline SOD3 & $15.18 \pm 2.11$ & $7.59 \pm 0.90^{* *}$ & $6.32 \pm 3.26^{* *}$ & 192.39 & 464.04 \\
\hline GPX1 & $0.52 \pm 0.22$ & $0.08 \pm 0.60$ & $0.32 \pm 0.63$ & 1.36 & 1.16 \\
\hline GPX4 & $0.44 \pm 0.31$ & $0.24 \pm 0.58$ & $0.77 \pm 0.72$ & 1.15 & 0.79 \\
\hline GPX7 & $9.69 \pm 0.66$ & $9.00 \pm 1.36$ & $6.66 \pm 1.02$ & 1.61 & 8.19 \\
\hline PRDX1 & $1.88 \pm 0.65$ & $1.12 \pm 0.62$ & $2.27 \pm 0.85$ & 1.69 & 0.76 \\
\hline HMOX1 & $5.30 \pm 0.14$ & $4.78 \pm 1.17$ & $4.89 \pm 1.73$ & 1.43 & 1.34 \\
\hline ALOX5 & $10.09 \pm 0.41$ & $8.96 \pm 0.89$ & $10.27 \pm 1.98$ & 2.19 & 0.88 \\
\hline DUOX1 & $15.56 \pm 1.93$ & $14.65 \pm 0.69$ & $12.65 \pm 4.02$ & 1.88 & 7.50 \\
\hline
\end{tabular}

Note: $* * \mathrm{P}<0.001$, Group 1 vs Group 2, Group 1 vs Group 3.

\section{Discussion}

Several studies indicated that space flights are associated with imbalance between oxidant production and antioxidant defense $[21,22,23,24,25,26]$. In animal models, it was observed that there was an increased oxidant concentration of malondialdehyde (MDA) and reactive oxygen species (ROS), what's more, there were reductions in antioxidant enzyme in serum, kidney and brain after simulated microgravity $[24,25,26]$. Researchers from the proteomic analysis of pulmonary tissue found that alteration in peroxidase expression played an important role in simulated weightlessness-induced lung injury [28].

However, there were not more evidences to confirm an association between oxidative stress and lung injury under microgravity. Consequently, to comprehensively analyze changes of oxidative stress in microgravity-induced lung injury, we established a ground-based model of stress which simulates those endured stress as a result of spaceflight. The antiorthostatic model has become the most widely available model of simulated microgravity. Rhesus macaque is a common substitute for human in many disease models. Hence, macaque suspended in the antiorthostatic position may be a useful model for investigating microgravity.

Our results showed that the concentration of $\mathrm{H}_{2} \mathrm{O}_{2}$ increased in plasma of rhesus macaque under long-term simulated microgravity. In terms of antioxidant, the levels of GSH in plasma of rhesus macaque were significantly lower under long-term simulated microgravity. This decreased antioxidant defense of GSH may be one of the reasons for observing increased levels of $\mathrm{H}_{2} \mathrm{O}_{2}$ in plasma of rhesus macaque and subsequent oxidative stress occurred under simulation microgravity conditions.

Oxidative stress can lead to a disruption of redox signaling, DNA and protein damage, as well as lipid peroxidation $[15,16]$. Therefore, we speculated that oxidative stress has been implicated in the pathogenesis of morphological changes and 
dysfunction in various organs systems under microgravity because indexes about oxidative stress in plasma are characteristics of oxidative stress in living body. Moreover, restoring GSH levels might be an effective preventive measure against various oxidative stresses under microgravity.

The lung is one of the most vulnerable organs that have great influences on spaceflight $[8,9]$. In this study we observed structural damage of alveolar walls, thickened alveoli septum, a few of lymphocytes infiltration in macaque lung tissues under simulated microgravity. The results of morphological damage were consistent with other studies [28, 29]. However, SOD and GSH levels in lung tissues did not significantly change under simulated microgravity. Additionally, we had examined the mRNA expression of antioxidant gene and the related genes' expression of oxidant stress in lung tissues. The results of this study indicated that the mRNA expression of SOD3 was up-regulated in macaque lung tissues under simulated microgravity. But other gene expressions were not significantly different among these groups.

The extracellular superoxide dismutase (EC-SOD, SOD3) is a major extracellular antioxidant enzyme that converts superoxide into hydrogen peroxide by reducing oxidative cell stress [30]. Because of secretion to extracellular space, the enzymes mainly located in the lymph, synovial fluid and plasma [31]. Our data assayed by qPCR indicated that SOD3 mRNA was increased in macaque lung tissues under simulated microgravity. But SOD levels in lung tissues did not significantly change under simulated microgravity. Furthermore, we only detected the total SOD activity and didn't reflect independently of SOD1, SOD2 and SOD3. Thus, our data demonstrated that oxidant stress was not a major factor involved in the development of lung damage under simulated microgravity. Further study is needed to clarify the mechanism about the lung injury under microgravity.

All in all, in a long-term simulated microgravity environment, systemic antioxidant level of GSH was reduced; on the contrary, an oxidative stress marker of $\mathrm{H}_{2} \mathrm{O}_{2}$ was increased. Meanwhile, long-term simulated microgravity caused lung injury and induced the mRNA of SOD3 expression in lung tissues. But oxidant stress is not a major factor involved in the development of lung damage under simulated microgravity.

\section{Acknowledgements}

This work was supported by the Major Programs of the Military Medical Science and Technique Foundation during 12th Five-Year Plan Period (BWS11J051), the key project for research on experimental technique of the General Armaments Department (SMFA13K02) and Science Foundation for Young Scientists of 306th Hospital of PLA (14QN04).

\section{References}

[1] Hughes-Fulford M. Altered cell function in microgravity. Exp Gerontol. 1991, 26: 247-256.

[2] Arbeille P, Provost R, Zuj K., Vincent N. Measurements of jugular, portal, femoral, and calf vein cross-sectional area for the assessment of venous blood redistribution with long duration spaceflight (Vessel Imaging Experiment). Eur J Appl Physiol. 2015, 115: 2099-2106.

[3] Liu Z, Wan Y, Zhang L, Tian Y, Lv K, Li Y, Wang C, Chen X, Chen S, Guo J. Alterations in the heart rate and activity rhythms of three orbital astronauts on a space mission. Life Sci Space Res (Amst). 2015, 4: 62-22.

[4] Paiva M, Estenne M, Engel LA. Lung volumes, chest wall configuration, and pattern of breathing in microgravity. J Appl Physiol (1985). 1989, 67: 1542-1550.

[5] McCarthy I, Goodship A, Herzog R, Oganov V, Stussi E, Vahlensieck M. Investigation of bone changes in microgravity during long and short duration space flight: comparison of techniques. Eur J Clin Invest. 2000, 30: 1044-1054.

[6] Aubert AE, Beckers F, Verheyden B. Cardiovascular function and basics of physiology in microgravity. Acla Cardiol. 2005, 60: 129-151.

[7] Alessandri N, Petrassi M, Tufano F, Dei Giudici A, De Angelis S, Urciuoli F, Alessandri C, De Angelis C, Tomao E. Functional changes cardiovascular: normobaric activity and microgravity in young healthy human subjects. Eur Rev Med Pharmacol Sci. 2012, 16: 310-315.

[8] West JB. Microgravity and the lung. Physiologist. 1991, 34: s8-s10.

[9] Prisk GK. Microgravity and the lung. J Appl Physiol (1985). 2000, 89: 385-389.

[10] Camhi SL, Lee P, Choi AM. The oxidative stress response. New Horiz. 1995, 3: 170-182.

[11] Draeqer J, Hanke K. Postural variations of intraocular pressure-preflight experiments for the D1-mission. Ophthalmic Research. 1986, 18: 55-60.

[12] Sonnenfeld G, Schaffar L, Schmitt DA, Peres C, Miller ES. The rhesus monkey as a model for testing the immunological effects of space flight. Adv Space Res. 1994, 14: 395-397.

[13] Convertino VA, Koenig SC, Krotov VP, Fanton JW, Korolkov VI, Trambovetsky EV, Ewert DL, Truzhennikov A, Latham RD. Effects of 12 days exposure to simulated microgravity on central circulatory hemodynamics in the rhesus monkeys. Acta Astronaut. 1998, 255-263.

[14] Tang C, Niu Z, Zheng Y, Chen Y, Bao B, Meng Q. Effects of hypergravity exposure after 30 -days simulated weightlessness on chemokine CCL20 and its receptor CCR6 in lingual mucosa of rhesus macaque. Zhonghua Yi Xue Za Zhi. 2014, 94: 2525-2530.

[15] Sies H. Role of metabolic $\mathrm{H}_{2} \mathrm{O}_{2}$ generation: redox signaling and oxidative stress. J Biol Chem. 2014, 289: 8735-8741.

[16] McCord JM, Edeas MA. SOD, oxidative stress and human pathologies: a brief history and a future vision. Biomed Pharmacother. 2005; 59: 139-142.

[17] Njâlsson R, Norgren S. Physiological and pathological aspects of GSH metabolism. Acta Paediatr. 2005, 94: 132-137.

[18] Sandalio LM, RodrÍguez-Serrano M, Romero-Puertas MC, del RÍo LA. Role of peroxisomes as a source of reactive oxygen species (ROS) signaling molecules. Subcell Biochem. 2013, 69: 231-255.

[19] Mailloux RJ. Teaching the fundamentals of electron transfer reactions in mitochondria and the production and detection of reactive oxygen species. Redox Biol. 2015, 4: 381-398. 
[20] Kurata M, Suzuki M, Agar NS. Antioxidant systems and erythrocyte life-span in mammals. Comp Biochem Physiol B. 1993, 106: 477-487.

[21] Markin AA, Zhuravlëva OA. Lipid peroxidation and antioxidant defense system in rats after a 14-day space flight in the "Space-2044" spacecraft. Aviakosm Ekolog Med. 1993, 27: 47-50.

[22] Markin AA, Popova 1A, Vetrova EG, Zhuravleva OA, Balashov OI. Lipid peroxidation and activity of diagnostically significant enzymes in cosmonauts after flights of various durations. Aviakosm Ekolog Med. 1997, 31: 14-18.

[23] Markin AA, Zhuravleva OA. Lipid peroxidation and indicators of antioxidant defence system in plasma and blood serum of rats during 14-day spaceflight on-board orbital laboratory “Spacelab-2”. Aviakosm Ekology Med. 1998, 32: 53-55.

[24] Chen HL, Qu LN, Li QD, Bi L, Huang ZM, Li YH. Simulated microgravity-induced oxidative stress in different areas of rat brain. Sheng Li Xue Bao. 2009, 61: 108-114.

[25] Rai B, Kaur J, Catalina M, Anand SC, Jacobs R, Teughels W. Effect of simulated microgravity on salivary and serum oxidants, antioxidants, and periodontal status. J Periodontol. 2011, 82: 1478-1482.
[26] Song Y, Ji B, Wang DS, Zhang H, Zhao BX, Xu Ys, Zhang P, Yang J, Huang YH, Liu YL, Ren XX, Zhu WL, Lu J. Effect of acupuncture at different time points on kidney function and oxygen free radical metabolism in rats with simulated weightlessness. Zhongguo Zhen Jiu. 2014, 34: 1106-1110.

[27] Wang J, Liu C, Li T, Wang Y, Wang D. Proteomic analysis of pulmonary tissue in tail-suspended rats under simulated weightlessness. J Proteomics. 2012, 75: 5244-5253.

[28] Glenny RW, Lamm WJ, Bernard SL, An D, Chornuk M, Pool SL, Wagner WW Jr, Hlastala MP, Roberston HT. Selected contribution: redistribution of pulmonary perfusion during weightlessness and increased gravity. J Appl Physiol (1985). 2000, 89: 1239-1248.

[29] Pei SJ, Zhu ML, Yi Y, Zhou JL, Xu BX, Wang P. Changes of anti-Streptococcus pneumoniae status in rats with simulated weightlessness. Zhonghua Jie He He Hu Xi Za Zhi. 2012, 35: 5515-519.

[30] Landis GN, Tower J. Superoxide dismutase evolution and life span regultaion. Mech Ageing Dev. 2005, 126: 365-379.

[31] Skrzycki M, Czeczot H. [Extracellular superoxide dismutase (EC-SOD)--structure, properties and functions]. Postepy Hig Med Dosw (Online). 2004, 58: 301-311. 